\title{
The Toll-Like Receptor TLR4 Is Necessary for Lipopolysaccharide- Induced Oligodendrocyte Injury in the CNS
}

\author{
Seija Lehnardt ${ }^{1 *}$ Christian Lachance, ${ }^{1 *}$ Silvia Patrizi, ${ }^{1 *}$ Sharon Lefebvre, ${ }^{1}$ Pamela L. Follett, ${ }^{2}$ \\ Frances E. Jensen, ${ }^{2}$ Paul A. Rosenberg, ${ }^{2}$ Joseph J. Volpe, ${ }^{2}$ and Timothy Vartanian ${ }^{1}$ \\ ${ }^{1}$ Department of Neurology, Beth Israel Deaconess Medical Center, Boston, Massachusetts 02115, 2Department of \\ Neurology, Children's Hospital, and Program in Neuroscience, Harvard Medical School, Boston, Massachusetts 02115
}

The immediate or innate immune response is the first line of defense against diverse microbial pathogens and requires the expression of recently discovered toll-like receptors (TLRs). TLR4 serves as a specific receptor for lipopolysaccharide (LPS) and is localized on the surface of a subset of mammalian cells. Although innate immunity is a necessary host defense against microbial pathogens, the consequences of its activation in the CNS can be deleterious, as we show here in a developing neural model. We examined the major non-neuronal cell types in the CNS for expression of TLR4 and found that microglia expressed high levels, whereas astrocytes and oligodendrocytes expressed none. Consistent with TLR4 expression solely in microglia, we show that microglia are the only CNS glial cells that bind fluorescently tagged lipopolysaccharide. Lipopolysaccharide led to extensive oligodendrocyte death in culture only under conditions in which microglia were present. To

Susceptibility to disease development or disease progression is associated with previous but nonspecific infection in perventricular leukomalacia (PVL), multiple sclerosis (Hernan et al., 2001; Kurtzke and Heltberg, 2001; Moses and Sriram, 2001; Yucesan and Sriram, 2001), and other CNS diseases. This relationship between systemic infection and CNS disease has been particularly well documented for PVL, which serves as a useful example. PVL accounts for most of the cerebral palsy and cognitive impairment encountered in survivors of premature birth (Volpe, 2001). The two pathologic hallmarks of PVL are focal necrosis with loss of all cellular elements and more diffuse white matter injury (Banker and Larroche, 1962; Gilles et al., 1983; Takashima et al., 1986) affecting principally oligodendrocyte precursors (Back et al., 2001). A relationship between systemic infection, circulating lipopolysaccharide (LPS), and the pathogenesis of PVL was suggested initially by studies of Gilles and coworkers (Gilles et al., 1976, 1977). In this work, systemic administration of LPS in neonatal animals resulted in forebrain white matter injury similar

\footnotetext{
Received Nov. 21, 2001; revised Jan. 2, 2002; accepted Jan. 15, 2002.

This work was supported by Grant NS38475 from the National Institute of Neurologic Disorders and Stroke (T.K.V.) and Grant P30HD18655 from Fonds de la Recherche en Santé du Québec (C.L.). S.P. was supported by a neonatology Fellowship from Tufts New England Medical Center. We thank Drs. Raj Ratan and Amyn Habib and the Vartanian lab for their helpful comments on this manuscript. *S.L., C.L., and S.P. contributed equally to this work.

Correspondence should be addressed to Timothy Vartanian, Harvard Institutes of Medicine, 77 Avenue Louis Pasteur, Boston, MA 02115. E-mail: tvartani@caregroup. harvard.edu.

C. Lachance's present address: St. Justine Hospital, Neonatology, University of Montreal, 3175 Cote St. Catherine, Montreal, Quebec, Canada H3T 1C5.

Copyright (C) 2002 Society for Neuroscience $0270-6474 / 02 / 222478-09 \$ 15.00 / 0$
}

determine whether TLR4 is necessary for lipopolysaccharideinduced oligodendrocyte death in mixed glial cultures, we studied cultures generated from mice bearing a loss-of-function mutation in the t/r4 gene. Lipopolysaccharide failed to induce oligodendrocyte death in such cultures, in contrast to the death induced in cultures from wild-type mice. Finally, stereotactic intracerebral injection of lipopolysaccharide into the developing pericallosal white matter of immature rodents resulted in loss of oligodendrocytes and hypomyelination and periventricular cysts. Our data provide a general mechanistic link between (1) lipopolysaccharide and similar microbial molecular motifs and (2) injury to oligodendrocytes and myelin as occurs in periventricular leukomalacia and multiple sclerosis.

Key words: myelination; glia; macrophage; regeneration; degeneration; demyelinating disease

to that seen in PVL (Gilles et al., 1976, 1977). Two recent demonstrations of cerebral white matter lesions in fetal rabbits after the induction of maternal intrauterine infection with Escherichia coli are consistent with the earlier observations (Yoon et al., 1997b; Debillon et al., 2000). In rats, maternal injection of LPS induced expression of the proinflammatory cytokines interleukin- $1 \beta$ (IL-1 $\beta$ ) and TNF- $\alpha$ in brains of offspring (Cai et al., 2000). In addition, a low dose of LPS increases the susceptibility of newborn rats to cerebral infarction in response to otherwise harmless periods of hypoxia-ischemia (Eklind et al., 2001). In humans, several lines of clinical evidence link intrauterine infection to the generation of PVL. Thus, the incidence of PVL and cerebral palsy in premature infants is increased in the presence of (1) evidence for maternal/fetal infection (Grether et al., 1996; Perlman et al., 1996; Zupan et al., 1996; Baud et al., 1998; Dammann et al., 1998; O'Shea et al., 1998; Hansen and Leviton, 1999; Leviton et al., 1999; Redline et al., 2000; Resch et al., 2000; Wu and Colford, 2000; De Felice et al., 2001) and (2) elevated levels of various cytokines in cord blood (Yoon et al., 1996), amniotic fluid (Yoon et al., 1997a), and neonatal blood (Grether et al., 1996, 1999; Nelson et al., 1998). Moreover, the demonstration of proinflammatory cytokines within PVL lesions is also supportive of a relationship between PVL and intrauterine infection, although this could potentially be a secondary effect of ischemia or other insults (Deguchi et al., 1996; Kadhim et al., 2001).

Because the bacterial sources of maternal/fetal infection associated with premature birth and PVL (Gibbs et al., 1992) are diverse, the possibility exists that the underlying mechanistic link is a feature of infection per se and not a specific organism. The 
innate immune response is activated by specific molecular motifs derived from a wide variety of pathogenic bacteria (Medzhitov and Janeway, 1997a; Imler and Hoffmann, 2000; Kaisho and Akira, 2000). The molecular and cellular basis for this innate immune response only recently is unfolding and currently is understood best for LPS. Circulating LPS binds to an LPSbinding-protein and to CD14. However, to exert its pathogenic effect, LPS requires TLR4, which is present on circulating monocytes/macrophages and other systemic immune cells (Poltorak et al., 1998; Hoshino et al., 1999; Qureshi et al., 1999; Zhang and Ghosh, 2001). Recently, the cellular localization of TLR4 mRNA was studied in the rat CNS. In addition to expression in the leptomeninges and choroid plexus, cells resembling microglia within the parenchyma were also positive for TLR4 (Laflamme and Rivest, 2001).

TLR4 is necessary for signal transduction induced by LPS and such cellular consequences of LPS stimulation as expression of reactive oxygen species and various cytokines. The potential link to the relationship of maternal/fetal infection and PVL is that oligodendrocytes have been shown to be vulnerable to injury by oxidative stress and proinflammatory cytokines (Woodroofe, 1991; Constam et al., 1992; Merrill et al., 1993; Benveniste, 1994; Benveniste et al., 1994, 1995; Benveniste and Benos, 1995; Vartanian et al., 1995; Woodroofe, 1995; Yonezawa et al., 1996). Moreover, in studies directly addressing the possibility of a maturation dependence of cytokine or oxidative stress-induced injury to oligodendrocytes, oligodendroglial precursors have been shown to be more vulnerable than mature cells (Oka et al., 1993; Yonezawa et al., 1996; Baerwald and Popko, 1998).

The purpose of this study was to determine whether the cellular mechanism by which LPS mediates oligodendrocyte and white matter injury involves the innate immune response and any other cell types in the CNS. We found that microglia expressed both CD14 and TLR4. Oligodendrocyte precursors, one of the major target cells injured in PVL (Back et al., 2001), expressed very low levels of CD14 but no TLR4. In addition, although LPS had no effect on highly purified preparations of these oligodendrocyte precursors, in mixed cultures LPS was a potent inducer of oligodendrocyte precursor death. Consistent with these observations, in Boyden chambers, LPS stimulated microglia-secreted factors that induced death of purified oligodendrocyte precursors. Moreover, in mixed glial cultures prepared from mice bearing a lossof-function mutation in the tlr4 gene, LPS had no effect on oligodendrocyte precursors. To explore the in vivo relevance of these in vitro findings, we evaluated the effects of LPS when it was stereotactically injected into the pericallosal area of the immature animal. We found that in vivo, LPS injured oligodendrocytes and induced white matter injury manifested by hypomyelination and cystic lesions, which are neuropathological characteristics of human PVL.

\section{MATERIALS AND METHODS}

$R T$-PCR. Relative levels of CD-14 and the toll-like receptor TLR4 mRNA in astrocytes, microglia, and oligodendrocytes were determined by RT-PCR. cDNA was synthesized from total RNA with oligo(dT) primers and Moloney murine leukemia virus reverse transcriptase (SuperScript II, Invitrogen, Gaithersburg, MD) at $42^{\circ} \mathrm{C}$ for $1 \mathrm{hr}$. cDNA from $2.5 \mu \mathrm{g}$ total RNA was used as a template for PCR amplification in a 50 $\mu \mathrm{l}$ reaction volume containing $1 \times$ PCR buffer, $0.1 \mathrm{~mm}$ dNTPs, and 0.1 $\mu \mathrm{M}$ each primer. Thirty cycles were performed using recombinant Taq DNA polymerase (Invitrogen) $\left(94^{\circ} \mathrm{C}\right.$ for $45 \mathrm{sec}, 60^{\circ} \mathrm{C}$ for $45 \mathrm{sec}$, and $72^{\circ} \mathrm{C}$ for $2 \mathrm{~min}$ ) and a final $10 \mathrm{~min} 72^{\circ} \mathrm{C}$ extension. In all experiments, amplification of $\beta$-actin was run in parallel to normalize samples. Primers used for PCR were obtained from Invitrogen: CD14, sense GTGCTC-
CTGCCCAGTGAAAGA, antisense GATCTGTCTGACAACCCTGAGT; TLR4, sense TTGAAGACAAGGCATGGCATGG, antisense TCTCCCAAGATCAACCGATG.

Primary culture preparation. Primary cultures of oligodendrocytes, microglial cells, and astrocytes were generated from the forebrains of 2- to 3-d-old Sprague Dawley rats as described previously (Vartanian et al., 1995). Briefly, brain tissue was triturated and dissociated with trypsin for $20 \mathrm{~min}$ at $37^{\circ} \mathrm{C}$. After mechanical dissociation, the cells were plated in DMEM supplemented with $10 \%$ fetal bovine serum (FBS) and penicillin/streptomycin. Mixed glial cultures containing oligodendrocytes, microglia, and astrocytes were maintained for different periods of time. After 1 week in culture, mixed glial cultures were shaken for $30 \mathrm{~min}$ at $180 \mathrm{rpm}$. The supernatants containing $>90 \%$ microglia were plated onto uncoated tissue culture plates, tissue culture inserts, or cover glasses. Fifteen minutes after plating, nonadherent cells (predominantly astrocytes and oligodendrocytes) were removed by three washes with PBS leaving cultures $>98 \%$ microglia by immunostaining. Microglia were maintained in DMEM with 5\% FBS. Oligodendrocyte progenitors were isolated from the remaining adherent cells by a second shake of $12 \mathrm{hr}$ at $180 \mathrm{rpm}$. After this second shake the supernatant was preplated on tissue culture flasks for $1 \mathrm{hr}$ in the presence of leucine methyl ester (a specific macrophage/microglial toxin) and passed successively through 20 and 10 $\mu \mathrm{m}$ mesh filters, removing most of the contaminating astrocytes and microglia (Giulian et al., 1994a, 1995; Vartanian et al., 1995; Hewett et al., 1999). Enriched oligodendroglia were plated on poly-D-lysine-coated cover glasses in serum-free DMEM with BSA, N2 supplements, PDGF-AA (10 ng/ml) and basic FGF (10 ng/ml). One-half of the media was exchanged with fresh media every $2 \mathrm{~d}$. These enriched oligodendrocyte cultures were assayed for contamination by microglia and astrocytes for each preparation. Typically cultures contained $\sim 0.5-2 \%$ microglia cells as assessed by uptake of diI-acetyl low density lipoprotein depending on the preparation (data not shown). For LPS experiments on oligodendrocytes directly or in Boyden chambers, only preparations containing $0.5 \%$ microglia or less were used. Two days before experimentation, cultures were switched to medium containing N2 supplements to allow cells to develop to the O4+/O1- stage (Barres et al., 1993; Gard and Pfeiffer, 1993). Under these conditions, $>95 \%$ of the cells were O4 ${ }^{+}$ and $<5 \%$ were $\mathrm{O} 1$ positive. In this paper we use the term oligodendrocyte precursor to denote an $\mathrm{O} 4+/ \mathrm{O} 1-$ oligodendrocyte.

Mixed glial cultures were prepared from the forebrain of $l p s^{d}$ and wild-type (WT) mice by procedures identical to those described for preparation of the rat brain cultures. However, in the former case, forebrains were isolated from embryonic day 17 embryos. Mouse cells were cultured in DMEM containing $0.05 \%$ BSA, $2 \%$ FBS, and N2 additives.

Immunofluorescence microscopy. For O4 immunofluorescence, live cultures were incubated for $15 \mathrm{~min}$ with the $\mathrm{O} 4$ monoclonal antibody ( $\mathrm{mAb}$ ), washed with PBS, then fixed in fresh $4 \%$ paraformaldehyde in PBS for 7 min at ambient temperature, washed with PBS, then incubated with the relevant secondary antibody (Jackson ImmunoResearch) and visualized by epifluorescence. For GFAP immunofluorescence, cells were treated with $0.125 \%$ Triton X-100 in PBS for 20 min before incubation with primary antibody. Primary antibodies used were against the following: O4 (American Type Cell Culture) and GFAP (Boehringer Mannheim). Immunofluorescent images were obtained using a Nikon Eclipse 660 Microscope with $20 \times, 40 \times$, and $60 \times$ objectives, and a Spot cooled CCD. For direct staining with fluorescently tagged LPS, living cells were incubated with Alexa 488-conjugated LPS (E. coli or Salmonella; Molecular Probes, Eugene, OR) in serum-free medium at $37^{\circ} \mathrm{C}$ for $1 \mathrm{hr}$, washed three times with PBS, then directly visualized, and images were captured with a Spot cooled CCD. Microglial cells were labeled by staining with the isolectin-B4 (IB4) (Molecular Probes).

LPS toxicity studies. The effect of LPS on oligodendrocyte viability was assessed in highly enriched cultures of oligodendrocyte precursors in Boyden chambers with a second cell type in the upper chamber and in mixed glial cultures. All experiments on enriched oligodendrocyte precursors alone and enriched oligodendrocyte precursors in Boyden chambers used preparations of oligodendrocyte precursors that contained $<0.5 \%$ contaminating microglia. This low level was essential because even $2-5 \%$ microglial contamination was sufficient to induce oligodendrocyte injury by LPS (data not shown). Two preparations of LPS were used [E. coli O55:B5 (Calbiochem) or O11:B4 (Sigma, St. Louis, MO)], and similar results were obtained with each of these. LPS was added to enriched cultures of oligodendrocyte precursors $2 \mathrm{~d}$ after plating for $5 \mathrm{~d}$. For Boyden chamber experiments, enriched oligodendrocyte precursors 
were placed in the lower chamber on cover glasses. Upper chamber inserts contained microglia, astrocytes, rat fibroblasts, or no cells. LPS was added to the upper chamber for $48 \mathrm{hr}$ at a concentration of 100 $\mathrm{ng} / \mathrm{ml}$. For toxicity studies on oligodendrocyte precursors in mixed glial preparations, LPS was added directly to the cultures for 2-5 $\mathrm{d}$ as indicated. In mixed cultures, the ratio of oligodendrocytes over total number of cells was established by counting immunopositive oligodendrocyte precursors $\left(\mathrm{O}^{+}\right)$and bisbenzimide (Hoechst)-positive nuclei in six different fields $(200 \times)$ from each of four coverslips per experimental point. Each experiment was repeated four or five times. The effects of LPS on the viability of enriched cultures of astrocytes or oligodendrocyte precursors was assessed by MTT assays in 48-well plates. Reduction of the tetrasodium dye MTT to a formazan product (maximal optical density $510 \mathrm{~nm}$ ) was used for quantitation of cell survival (Celltiter, Promega).

Intracerebral stereotactic injection. Long-Evans rats (weight 14.96$20.04 \mathrm{gm}$ ) at postnatal day 7 were anesthetized in an ether chamber. A scalp incision along the sagittal suture was performed to access the skull, and a stereotactic drill was used to perforate the bone. Microinjections with a sharp beveled glass micropipette were conducted using stereotactic coordinates $1 \mathrm{~mm}$ posterior and $1 \mathrm{~mm}$ lateral to bregma and $2 \mathrm{~mm}$ below the dura. Lipopolysaccharide (E. coli 011:B4, Sigma), $5 \mu \mathrm{g}$ in $1 \mu \mathrm{l}$, or vehicle was injected into the pericallosal white matter, the micropipette was removed, and the scalp incision was sutured. Rats were euthanized $72 \mathrm{hr}$ or 3 weeks after injection with phenobarbital and then fixed by transcardial perfusion with PBS followed by $4 \%$ paraformaldehyde in PBS. Forebrains were post-fixed in $4 \%$ paraformaldehyde in PBS overnight, then cryoprotected in $30 \%$ sucrose. Coronal sections of $40 \mu \mathrm{m}$ were cut through the injection site with a freezing microtome, stored in PBS azide, and then mounted for immunohistochemical analysis. Oligodendrocytes and myelin were identified by staining with the mAb RIP (Developmental Studies Hybridoma Bank, Iowa City, IA). RIP recognizes an epitope expressed in both premyelinating and mature oligodendrocytes (Butt et al., 1997). Tissue sections were incubated overnight with RIP hybridoma supernatant with $2 \%$ Triton X-100, washed three times, and then incubated with the relevant secondary antibody (Cy3conjugated goat anti-mouse or biotinylated goat anti-mouse IgG) for $2 \mathrm{hr}$. Sections incubated with biotinylated secondary antibody were visualized using the avidin-biotin-peroxidase complex (ABC) method with 3,3'diaminobenzidine as chromogen. For each animal, six to eight sections in the area surrounding the injection site were examined by both light and fluorescence microscopy.

\section{RESULTS}

\section{The effect of LPS on oligodendrocytes is not cell autonomous}

Previous studies of cultured cells have shown a reduction in oligodendrocyte numbers in response to exposure to LPS (Merrill et al., 1993; Pang et al., 2000; Molina-Holgado et al., 2001). However, it has been unclear from this work whether the effect of LPS in inducing oligodendrocyte death is cell autonomous, and, if the effect is not cell autonomous, whether it is mediated through the action of astrocytes or microglia or both. To study the effect of LPS on oligodendrocyte precursor viability in an environment containing all CNS glial cell types (microglia and astrocytes, as well as oligodendrocyte precursors), mixed glial cultures that include $\mathrm{O}_{4}^{+}$oligodendrocyte precursors were prepared and then treated with $10 \mathrm{ng} / \mathrm{ml}$ LPS for $48 \mathrm{hr}$. Toxicity of LPS was measured by determining the ratio of the number of $\mathrm{O}^{+}{ }^{+}$oligodendrocytes to the total number of cells. LPS induced a dramatic reduction in numbers of oligodendrocyte precursors when compared with cultures not treated with LPS (Figs. 1A,B).

The effect of LPS in inducing oligodendrocyte death in mixed glial cultures was dose dependent (Fig. 1C). Even at extremely low doses of LPS (1 ng/ml), oligodendrocyte survival was significantly reduced. At $1 \mu \mathrm{g} / \mathrm{ml}$ LPS, there was approximately a fourfold reduction in the proportion of $\mathrm{O}^{+}$cells (Fig. 1C). Furthermore, the effects of LPS in inducing cell death were specific to the oligodendrocyte lineage. The numbers of astrocytes were unaffected by LPS treatment (data not shown).

To clarify whether these effects of LPS on oligodendrocyte survival were cell autonomous, we prepared highly purified cultures of oligodendrocyte precursors (see Materials and Methods), thus eliminating other cell types through which LPS could be acting. Cultures were used for study only if astrocytes comprised $<1 \%$ and microglia $<0.5 \%$ of the total cell number. These purified cultures of oligodendrocyte precursor cells were treated with LPS for $5 \mathrm{~d}$ in culture. The dose-response curve for concentrations of LPS up to $10 \mu \mathrm{g} / \mathrm{ml}$ failed to show any effect on oligodendrocyte survival (Fig. 1D). These data indicate that the toxicity of LPS on developing oligodendrocytes is not cell autonomous.

\section{Microglia are the major mediators of LPS toxicity to oligodendrocyte precursor cells}

Because LPS induced death of oligodendrocyte precursors in mixed glial cultures but not in purified oligodendroglial cultures, we sought to determine the cell type present in mixed glial cultures that responded directly to LPS and mediated oligodendroglial injury. Previous investigators have shown that LPS induces expression of inducible nitric oxide synthase as well as proinflammatory cytokines in cultured microglia and astrocytes (Merrill et al., 1993; Vartanian et al., 1995; Hartlage-Rubsamen et al., 1999; Hewett et al., 1999; Molina-Holgado et al., 2001). To determine the major cell type responsible for mediating the effects of LPS on cultured oligodendrocytes, we prepared purified cultures of astrocytes or microglia in Boyden chambers with $1 \mu \mathrm{m}$ pore diameters. In the lower chambers we placed purified cultures of oligodendrocyte precursor cells on coverslips. Astrocytes, microglia, or fibroblasts grown on semipermeable membranes in the upper chambers were treated for $48 \mathrm{hr}$ with LPS at $100 \mathrm{ng} / \mathrm{ml}$. Oligodendrocyte precursors in the lower chambers were quantitated by counting the number of $\mathrm{O}_{4}{ }^{+}$cells remaining at the end of the treatment period. Microglia treated with LPS, but not vehicletreated microglia, induced oligodendrocyte death in the Boyden chambers (Fig. 2). In contrast, astrocytes treated with LPS did not significantly influence oligodendrocyte viability (Fig. 2).

\section{Microglia specifically bind LPS in vitro}

The above result (Fig. 2) suggests that microglia are the major or sole targets of LPS in the CNS. If this were the case, we would then expect microglia to bind LPS specifically and astrocytes and oligodendrocytes not to bind LPS. To study LPS binding to CNS glia, we made use of fluorescently tagged LPS (see Materials and Methods) to identify high-affinity binding sites on the cells. Primary cultures of oligodendrocyte precursors, astrocytes, and microglia were incubated with LPS-Alexa at a concentration of 1 or $10 \mu \mathrm{g} / \mathrm{ml}$ for $1 \mathrm{hr}$. Cells were then washed and immediately visualized by fluorescence microscopy. Microglia were labeled intensely with LPS-Alexa, whereas astrocytes and oligodendrocytes showed no labeling (Fig. 3).

\section{Microglia express the toll-like receptor TLR4}

Because the receptors CD14 and TLR4 are required for the molecular and cellular effects of LPS in circulating monocytes (Means et al., 2000, 2001; Medzhitov and Janeway, 2000; Zhang and Ghosh, 2001), we next determined whether these receptors are expressed in CNS microglia or other glial cells. Microglia have been shown to express CD14 (Becher et al., 1996; Lacroix et al., 1998). To determine the cells in the CNS that express TLR4 as well as CD14, we prepared highly purified cultures of microglia, 
A

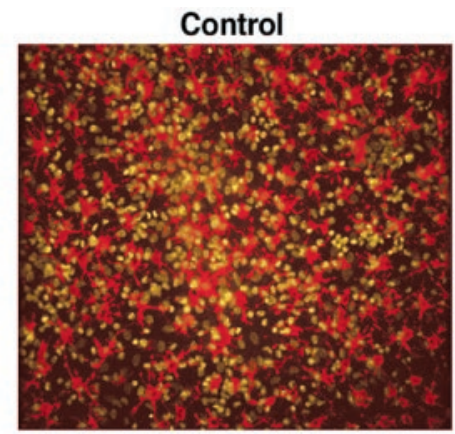

LPS

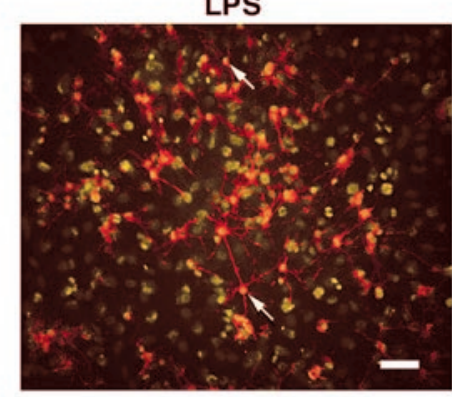

B

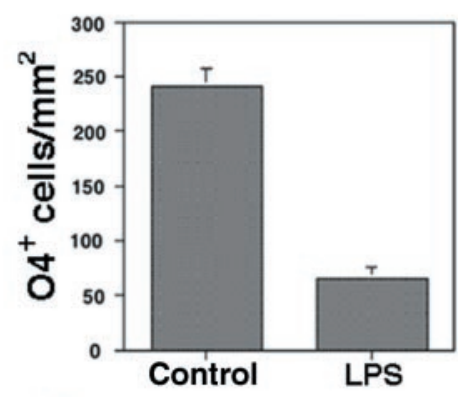

C

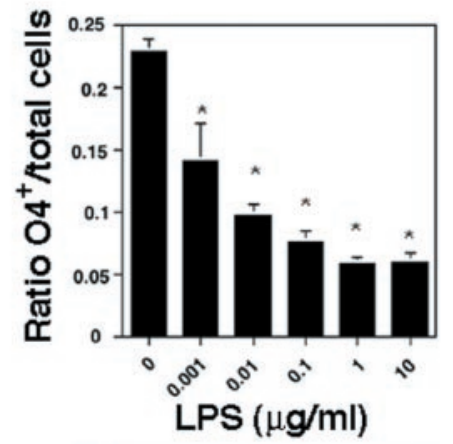

D

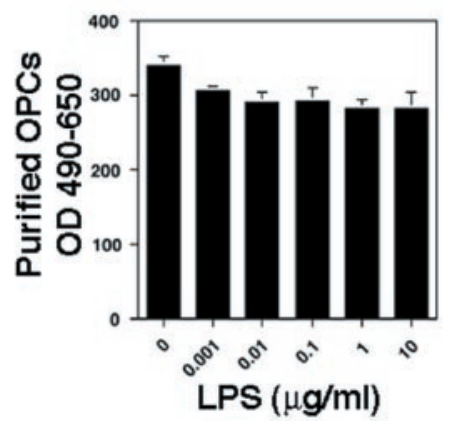

Figure 1. LPS-induced oligodendrocyte precursor death is not cell autonomous. Mixed glial or highly enriched oligodendrocyte precursor cultures were studied for LPS-induced oligodendrocyte injury. Scale bar, $50 \mu \mathrm{m}$. $A$, LPS induces oligodendrocyte precursor death in mixed glial cultures. Control and LPS-treated mixed glial cultures were stained for O4. LPS treatment for $5 \mathrm{~d}$ induced a prominent reduction in oligoden-

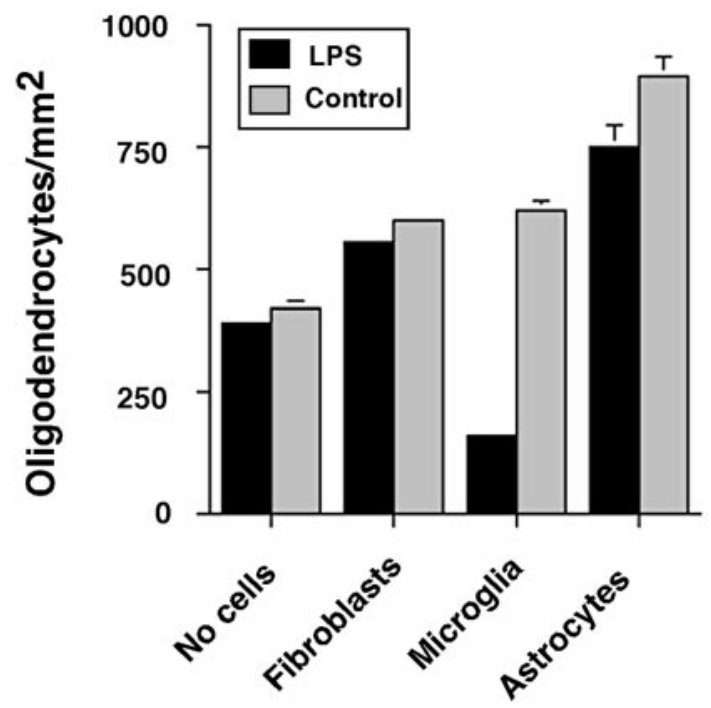

Figure 2. Activated microglia mediate oligodendrocyte precursor injury in response to LPS. Enriched populations of oligodendrocyte precursors grown on coverslips were exposed to secreted products of fibroblasts, astrocytes, and microglia in Boyden chambers. Upper chamber cells were treated with control buffer or LPS for $48 \mathrm{hr}$, and the $\mathrm{O}^{+}{ }^{+}$oligodendrocyte precursors in the lower chamber were quantitated by $\mathrm{O}^{+}{ }^{+}$immunostaining. In the absence of LPS, secreted products from fibroblasts, astrocytes, and microglia appeared to provide trophic support for oligodendrocyte precursors. Only LPS-stimulated microglia caused a significant reduction in oligodendrocyte precursor numbers. LPS-stimulated astrocytes or fibroblasts did not cause a significant reduction in $\mathrm{O}_{4}{ }^{+}$oligodendrocyte precursors. Experiments were performed three times, and results are shown as the mean $\pm \mathrm{SD}$.

astrocytes, and oligodendrocyte precursors from the forebrains of newborn rats. Purity of cultures was assessed by immunocytochemistry as described in Materials and Methods. Total RNA was isolated from individual cultures and reverse transcribed, and PCR was performed using primers specific for rat CD14 or TLR4. Microglia clearly express both TLR4 and CD14 (Fig. 4A). Transcripts for CD14 were also detected in astrocytes (Fig. 4A). A much smaller amount of CD14 transcript was detected in the oligodendrocyte precursor cells (Fig. 4A). Neither astrocytes nor oligodendrocyte precursors expressed TLR4 (Fig. 4A). These findings support the hypothesis that microglia are the major cell type within the CNS capable of transducing LPS signals.

A previous study showed that TLR4 expression in the CNS was decreased in some animals after systemic LPS treatment and was consistently diminished by the combination of LPS and hypoxiaischemia (Eklind et al., 2001). We thus studied TLR4 expression in mixed glial cultures 6 and $24 \mathrm{hr}$ after LPS treatment by

$\leftarrow$

drocyte precursor numbers. $B$, Quantitation of $\mathrm{O}^{+}{ }^{+}$oligodendrocyte precursors in mixed glial cultures after control and LPS treatment. Experiments were performed six times, and results are presented as the mean \pm SD. ${ }^{*} p<0.01$. $C$, Dose-response for LPS-induced oligodendrocyte injury. Mixed glial cultures were treated with increasing doses of LPS, and the $\mathrm{O}^{+}{ }^{+}$oligodendrocyte precursors were identified by immunofluorescence microscopy. Results are presented as the ratio of $\mathrm{O}^{+}$ cells to total cell number as determined by nuclear staining with bisbenzimide. $D$, The effects of LPS on oligodendrocyte precursor viability are not cell autonomous. Enriched cultures of oligodendrocyte precursors were treated with LPS at the concentrations indicated and then studied for survival using an MTT cell viability assay. Oligodendrocyte precursor numbers were unaffected in enriched cultures lacking microglia. 

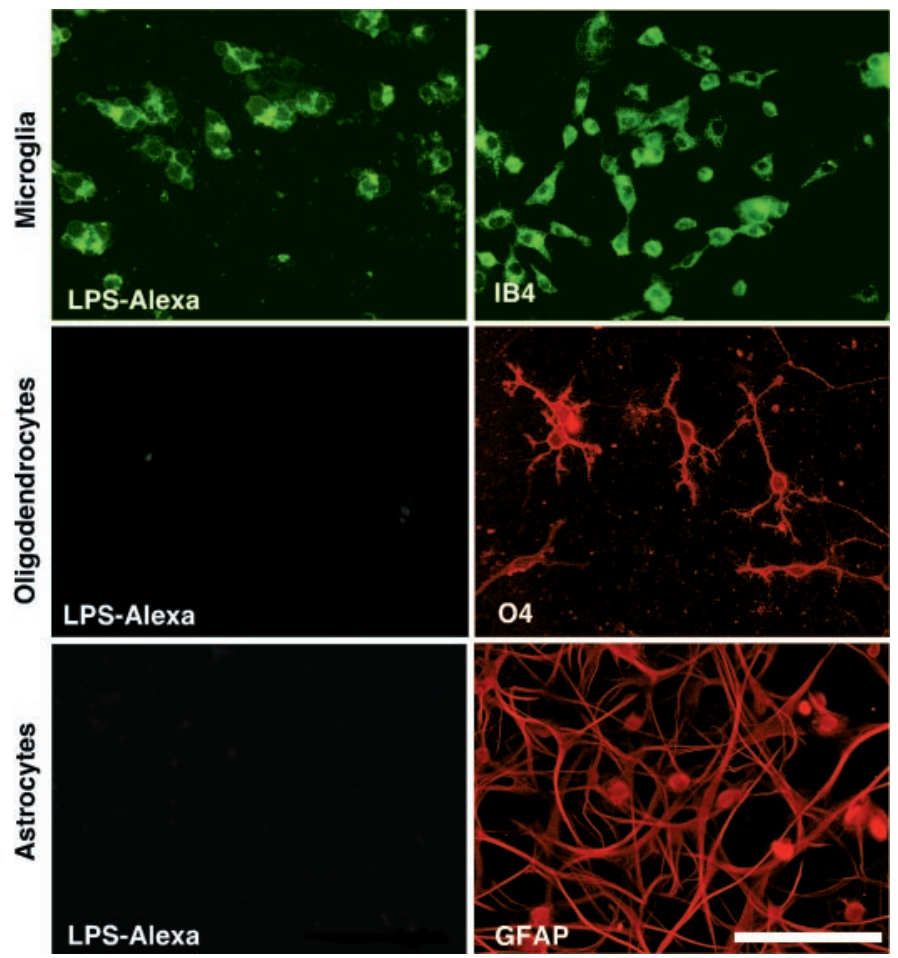

Figure 3. LPS binds to microglia but not astrocytes or oligodendrocytes. Enriched cultures of microglia, astrocytes, or oligodendrocytes were studied for binding of fluorescently labeled LPS. Intense fluorescence, indicating LPS binding, was observed in cultures of microglia but not astrocytes or oligodendrocytes. Parallel cultures shown on the right panels were stained to identify microglia (IB4), oligodendrocyte precursors $(O 4)$, or astrocytes $(G F A P)$. Similar results were obtained in three experiments. Scale bar, $100 \mu \mathrm{m}$.

RT-PCR. We found no change in levels of TLR4 expression in mixed glial cultures after either 6 or 24 hr of LPS exposure (Fig. $4 B)$. CD14 levels did appear to increase in response to LPS under these conditions (Fig. 4B).

\section{TLR4 is necessary for LPS-mediated injury to developing oligodendrocytes}

We next addressed the question of whether TLR4 is necessary for LPS-mediated oligodendroglial precursor death. The LPS hyporesponsive phenotype of the $\mathrm{C} 3 \mathrm{H} / \mathrm{HeJ}$ mouse (lps ${ }^{d}$ locus) results from a missense mutation in the tlr4 gene. As a result of this coding sequence mutation, no detectable TLR4 protein is synthesized (Poltorak et al., 1998; Hoshino et al., 1999; Qureshi et al., 1999). We took advantage of this naturally occurring defect in TLR4 signal transduction to examine the importance of TLR4 in LPS-mediated oligodendrocyte precursor injury. Mixed CNS forebrain cultures were prepared from $\operatorname{lps}^{d}$ and control mice (BALB/cJ). After $14 \mathrm{~d}$, cultures were treated with $10 \mu \mathrm{g} / \mathrm{ml}$ LPS or control solution for $5 \mathrm{~d}$, and oligodendrocyte precursor numbers were quantitated by $\mathrm{O} 4$ immunostaining. The numbers of $\mathrm{O}^{+}{ }^{+}$oligodendrocyte precursors in control cultures from $l p s^{d}$ and WT mice were indistinguishable (Fig. $5 A, B$ ). As in mixed glial cultures from WT rat forebrain, LPS induced major loss of ${ }^{+}{ }^{+}$ oligodendrocyte precursors in mixed glial cultures from WT mouse forebrain (Fig. 5A,B). However, LPS treatment had no effect on oligodendrocyte precursor numbers in cultures from $\mathrm{lps}^{d}$ mice (Fig. $5 A, B$ ). Similar results were obtained when the data were analyzed with respect to the total number of cells in culture

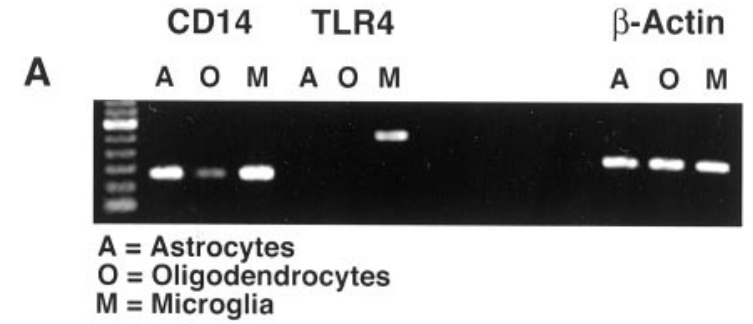

B

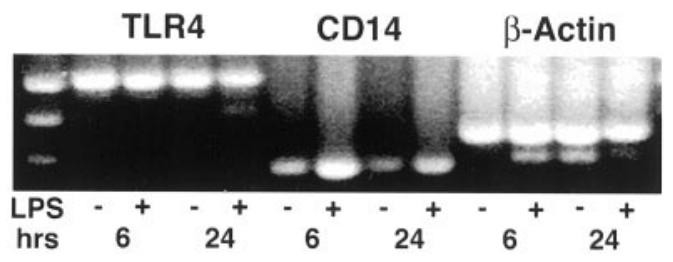

Figure 4. A, TLR4 is expressed in microglia. Total RNA was extracted from purified cultures of oligodendroglial precursors, microglial cells, and astrocytes. CD14 mRNA was detected in both astrocytes and microglia. TLR4 mRNA was detected only in microglia. $B$, LPS treatment of mixed glial cultures does not effect TLR4 expression. Mixed CNS glial cultures were treated with LPS or control solution for 6 or $24 \mathrm{hr}$. Transcripts for TLR4, CD14, and $\beta$-actin were identified by RT-PCR. TLR4 mRNA levels are unchanged by LPS treatment. CD14 mRNA levels appear to be increased after LPS treatment.

assessed by 4',6-diamidino-2-phenylindole staining. Extracellular potassium has been shown previously to enhance LPS-induced neurotoxicity (Chang et al., 2000). We evaluated the effect of elevated extracellular potassium on LPS-mediated oligodendrocyte injury in WT and $l p s^{d}$ cultures. Elevated extracellular potassium (20 mM) did not statistically enhance LPS-mediated oligodendrocyte precursor injury (Fig. 5B). Furthermore, $20 \mathrm{~mm}$ potassium did not influence oligodendrocyte precursor numbers in $l p s^{d}$ cultures in the presence or absence of LPS. To be certain that the percentage of microglia did not differ between $l p s^{d}$ and WT mixed glial cultures, microglia were quantitated by IB4 staining. No differences in microglial numbers or morphology were detectable between WT and $l p s^{d}$ cultures (Fig. 5C). These data indicate that the toll-like receptor TLR4 is necessary for LPS-mediated injury to oligodendrocytes in mixed glial cultures.

\section{Focal injection of LPS into developing cerebral white matter results in hypomyelination}

To determine whether the effects of LPS that we observed in vitro were relevant to oligodendrocyte injury in vivo, we injected LPS or vehicle stereotactically into the developing white matter of neonatal rats at postnatal day 7 . This in vivo model was used to avoid the potential hemodynamic effects of systemic injection. Of the total of 16 brains injected, 10 received LPS and 6 received vehicle. Animals then were studied after either $72 \mathrm{hr}$ or 3 weeks. Five LPS-injected and three vehicle-injected animals were studied at each time point. At neither time point did the animals exhibit alterations in behavior or somatic growth. No abnormalities were noted in the vehicle-injected control group on either gross examination or RIP immunostaining when compared with uninjected controls (data not shown). Coronal sections from vehicle-injected animals after $72 \mathrm{hr}$ showed a uniform distribution of oligodendrocytes in the corpus callosum and pericallosal white matter (Fig. 6A). The distribution in the contralateral uninjected hemisphere was identical (Fig. 6A). In contrast, there was clear evidence from RIP immunostaining for hypomyelination $72 \mathrm{hr}$ after LPS injection. Within the corpus callosum adjacent to the 
A
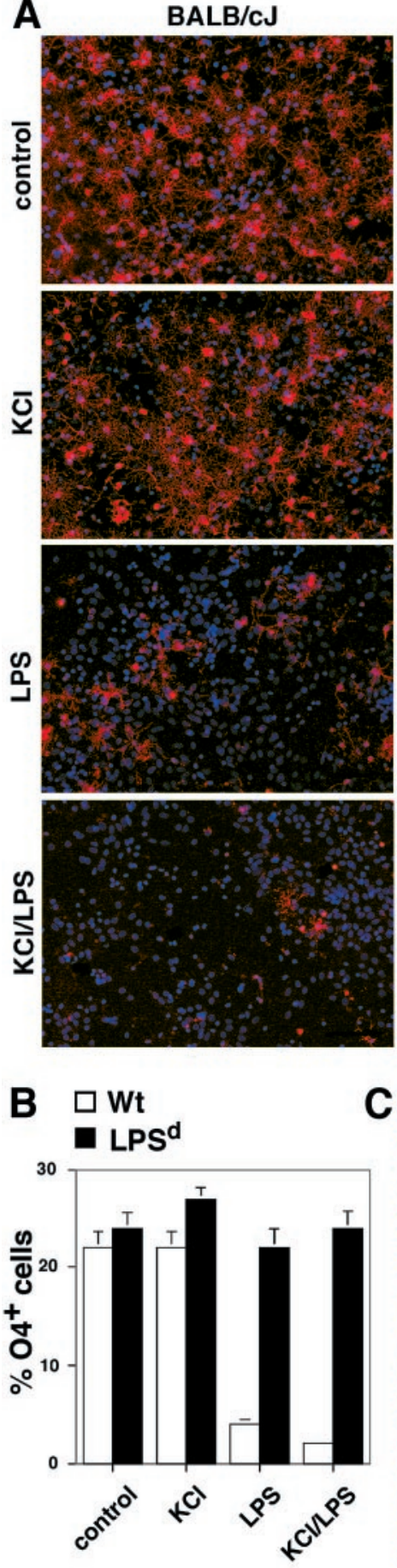
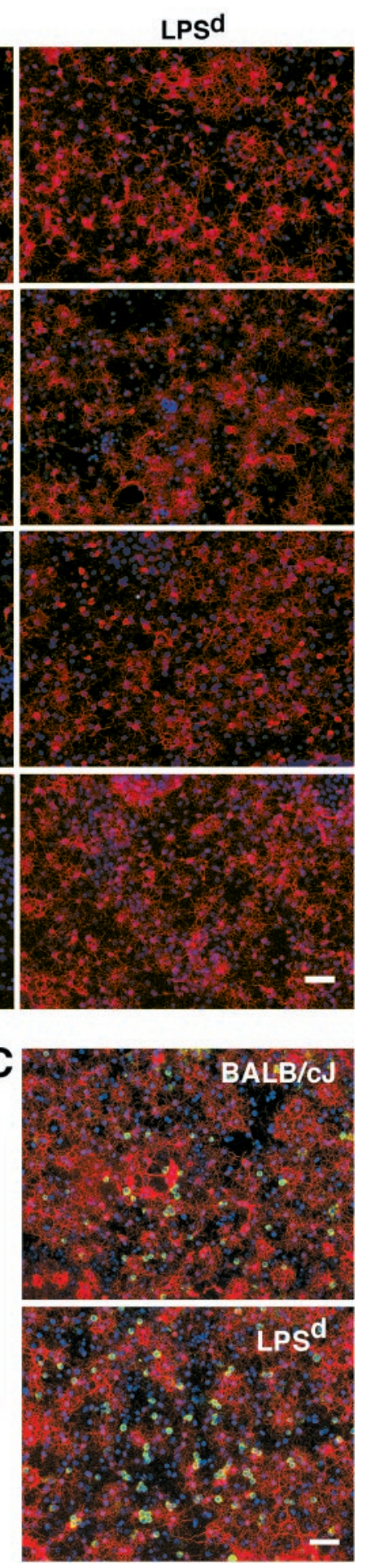

Figure 5. TLR4 is necessary for LPS-mediated oligodendrocyte precursor injury. Mixed glial cultures from WT and $\operatorname{lps}^{d}$ mouse forebrains were treated with LPS $(10 \mu \mathrm{g} / \mathrm{ml})$ or control buffer for $5 \mathrm{~d}$. Oligodendrocyte precursors were then quantitated by counting $\mathrm{O}^{+}{ }^{+}$cells. $A$, Fluorescent micrographs of control and LPS-treated mixed CNS glial cultures from $\mathrm{WT}$ and $\operatorname{lps}^{d}$ mice. Numerous oligodendrocyte precursors are observed in mixed glial cultures from WT and $l p s^{d}$ mice in the absence of LPS treatment. With LPS treatment there is a marked reduction in oligodendrocyte precursors in cultures from WT but not $l p s^{d}$ mice. Scale bar, 50 $\mu \mathrm{m}$. $B$, Quantitation of $\mathrm{O}^{+}{ }^{+}$oligodendrocyte precursors from WT and $\operatorname{lps}^{d}$ mice in the presence or absence of LPS. Treatment of mixed glial cultures from WT mice with LPS resulted in a sixfold reduction in oligodendrocyte precursors $(p<0.001)$. Oligodendrocyte precursor num-
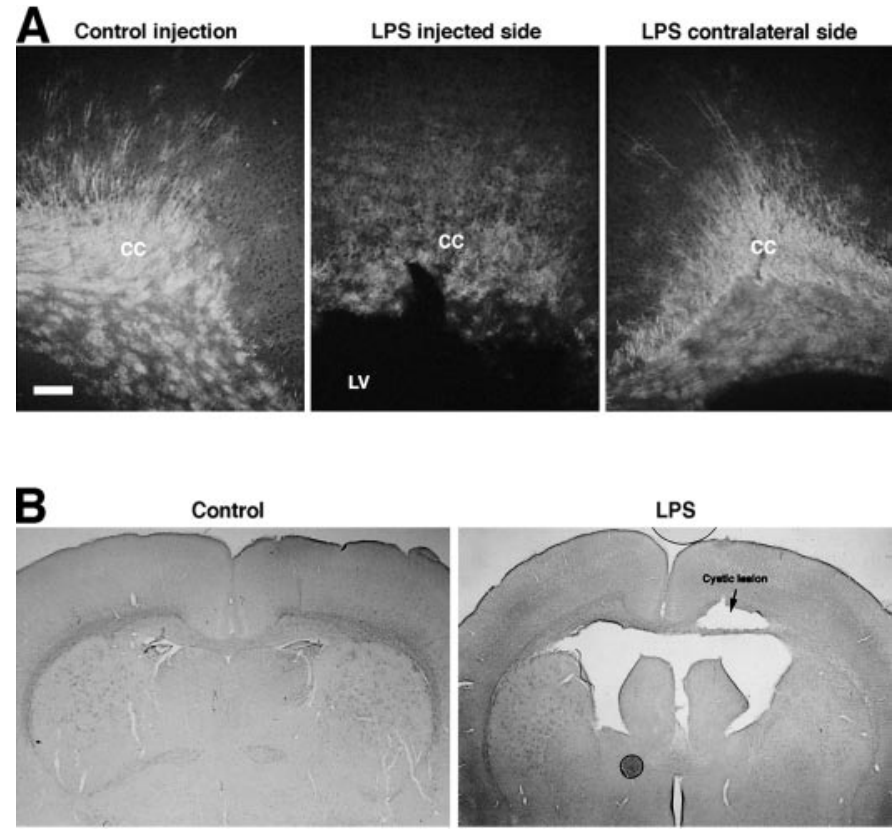

Figure 6. LPS induced lesions in the pericallosal area of the immature rodent. $A$, Coronal brain sections from 10 -d-old rats, $72 \mathrm{hr}$ after intracerebral injection of LPS or PBS as a control, immunostained with RIP. The ipsilateral LPS-injected brain area shows a reduction in the size of the corpus callosum $(c c)$, absence of RIP immunostaining in the periventricular region, and an enlarged lateral ventricle. The contralateral side of the LPS-treated brain has an intact corpus callosum and a homogeneous distribution of RIP immunoreactivity. $B$, Coronal sections from 10-d-old rat immunostained with RIP by the avidin-biotin method. In the control (PBS) injected animal, RIP immunoreactivity is most abundant in the pericallosal area, and there is no evidence of macroscopic histological abnormalities. The LPS-injected brain shows enlargement of lateral ventricles, a cystic lesion on the side of the injection, and decreased immunoreactivity in the corpus callosum on the injected side.

LPS injection site there was a marked reduction in RIP immunoreactivity (Fig. 6A). In addition, few myelinating oligodendrocytes were noted by RIP immunostaining in the pericallosal white matter relative to the abundant staining in the controls (Fig. 6 $A$ ).

Gross histologic abnormalities were identified qualitatively in the majority of LPS-injected brains but were never observed in the vehicle-injected brains. After $72 \mathrm{hr}$, three of five LPS-injected animals and, after 3 weeks, four of five of LPS-injected animals were noted to have enlarged ventricles (Fig. 6B). Additionally, after $72 \mathrm{hr}$, cystic lesions near or at the LPS injection site were found in three of five LPS-injected animals, and after 3 weeks, in two of five of the LPS-injected animals (Fig. 6B).

\section{DISCUSSION}

This report has addressed the cellular mechanism by which LPS mediates injury to oligodendroglial precursors, the cell type injured in human PVL (Back et al., 2001; Volpe, 2001). The findings suggest that the oligodendroglial injury results from

$\leftarrow$

bers in $l p s^{d}$ cultures were unaffected by LPS treatment. Similar results were obtained in three experiments, and results are presented as the mean \pm SD. $p<0.001$. $C$, The quantity of microglia is normal in the $l p s^{d}$ mouse. To determine the relative number of microglia in WT and $l p s^{d}$ mice, mixed glial cultures were stained with the microglia 1-specific isolectin IB4. No quantitative differences in microglial numbers were identified between $l p s^{d}$ and WT mice. Scale bar, $50 \mu \mathrm{m}$. 
activation of the innate immune response in microglia. The data have implications for the relationship of infection and the role of the innate immune response in the pathogenesis of cellular injury in the brain.

Maternal/fetal infection is an important pathogenetic factor in a large subset of infants with PVL. Clinical, epidemiological and neuropathological data support this contention (see introductory remarks for review). Both clinical and experimental findings suggest a particularly important role for Gram-negative bacteria and their cell wall component LPS (Gilles et al., 1976, 1977; Yoon et al., 1997b; Cai et al., 2000; Debillon et al., 2000). Potential explanations for the relationship between intrauterine infection and PVL include such deleterious effects of microbial products and cytokines as the induction of premature labor and delivery, the genesis of cerebral ischemia by infection-induced hypotension, and impaired cerebrovascular autoregulation, or the direct injury of oligodendroglial precursor cells (Volpe, 2001). However, none of these explanations adequately delineates how the diverse spectrum of microbials associated with intrauterine infection and the wide variety of potentially deleterious molecular products associated with these microbials might lead to the same result, i.e., oligodendroglial death. Our findings suggest that the unifying link between oligodendroglial death and these diverse microbes and associated molecular structures is activation of the innate immune response in microglia.

The innate immune response is the first line of defense against invading microbials (Janeway, 1992; Medzhitov and Janeway, 1997b; Means et al., 2000; Zhang and Ghosh, 2001). This response requires a series of microbial pattern recognition receptors that bind specific microbial-derived molecular motifs. It now appears that the toll-like receptors serve the important function of microbial pattern recognition receptors. A prototypical example of the innate immune response is mediated by the action of LPS on circulating monocytes and macrophages. In these bone marrow-derived cells, the toll-like receptor TLR4 is required for transducing the LPS signals (Poltorak et al., 1998; Hoshino et al., 1999; Qureshi et al., 1999). Because microglia are bone marrowderived monocytes that are found in the CNS early in development (Hickey and Kimura, 1988; Hickey et al., 1992), we hypothesized that these glial cells would express TLR4 and serve as the primary mediator of innate immune-mediated oligodendroglial injury. In this study we showed that microglia were the only glial cell type that expressed TLR4. Neither the cell destroyed by LPS activation, the oligodendroglial precursor cell, nor the astrocyte expressed TLR4. Consistent with these findings, microglia but not astrocytes or oligodendrocytes bound fluorescently labeled LPS. Moreover, in oligodendroglial cultures derived from WT mice expressing normal TLR4, LPS induces significant injury to developing oligodendrocytes. However, in cells bearing a loss-offunction mutation in the $t l r 4$ gene ( $l p s^{d}$ mouse), oligodendrocyte precursor numbers were unaffected by LPS treatment. These findings strongly implicate the innate immune response, and in particular the TLR4 pathway in LPS activation of microglia and thereby bystander injury to oligodendrocyte precursors. Of note, a relationship between innate immunity and regeneration in the CNS has also been proposed (Schwartz et al., 1999), although the molecular and cellular basis is not well understood.

Injury to oligodendrocytes can occur as the consequence of several specific mechanisms (Barres et al., 1992; Louis et al., 1993; Merrill et al., 1993; Cassaccia-Bonnefil et al., 1996; D’Souza et al., 1996; Trapp et al., 1997; McDonald et al., 1998; Fern and Moller, 2000). The mechanism by which activation of innate immunity leads to bystander injury of oligodendrocyte precursors is not known, but considerable in vitro data implicate both oxidative stress and proinflammatory cytokines. LPS-activated microglia synthesize a wide variety of reactive oxygen species (Boje and Arora, 1992; Merrill et al., 1993; Mitrovic et al., 1994; Park et al., 1994; Chao et al., 1995; Vartanian et al., 1995; Hewett et al., 1999; Possel et al., 2000), as well as numerous cytokines (Gebicke et al., 1994; Giulian et al., 1994b; Lee et al., 1994; Mizuno et al., 1994; Shrikant et al., 1995; Vartanian et al., 1995; Cai et al., 2000). Oligodendroglial precursor cells have been shown to be exquisitely vulnerable to reactive oxygen species and to specific proinflammatory cytokines (Woodroofe, 1991, 1995; Constam et al., 1992; Merrill et al., 1993; Benveniste, 1994; Benveniste et al., 1994, 1995; Benveniste and Benos, 1995; Vartanian et al., 1995; Yonezawa et al., 1996). Importantly, in studies specifically evaluating the vulnerability of the oligodendroglial lineage to these effectors, oligodendroglial precursor cells have been shown to be more vulnerable than mature cells (Oka et al., 1993; Yonezawa et al., 1996; Baerwald and Popko, 1998). Taken together these observations suggest that activation of the innate immune response in microglia in the developing brain can lead to death of oligodendroglial precursor cells in white matter, with sparing of astrocytes, a constellation of findings characteristic of human PVL of the premature infant (Volpe, 2001).

In conclusion, this research suggests that the underlying mechanistic link between the diverse microbes associated with maternal/fetal infection and PVL involves activation of the innate immune response. Microglia, known to be present in the early phases of evolution of PVL (Kadhim et al., 2001), represent the CNS cell type involved in this activation. The toll-like receptor TLR4 appears to be crucial in mediating the microglial activation by LPS, a clinically relevant, prototypical mediator of the innate immune response. These observations do not preclude other deleterious effects of maternal/fetal infection regarding PVL, e.g., induction of premature birth, cerebral ischemia, or direct injury to oligodendroglial precursor cells. Nevertheless, the findings suggest a novel mechanistic link between diverse infections and PVL. The possibility is raised that blocking the innate immune response by targeting the TLR4 pathway would be beneficial in preventing or limiting oligodendroglial injury in PVL caused by a wide variety of bacterial pathogens.

\section{REFERENCES}

Back SA, Luo NL, Borenstein NS, Levine JM, Volpe JJ, Kinney HC (2001) Late oligodendrocyte progenitors coincide with the developmental window of vulnerability for human perinatal white matter injury. J Neurosci 21:1302-1312.

Baerwald KD, Popko B (1998) Developing and mature oligodendrocytes respond differently to the immune cytokine interferon-gamma. J Neurosci Res 52:230-239.

Banker BQ, Larroche JC (1962) Periventricular leukomalacia of infancy. Arch Neurol 7:386-410.

Barres BA, Hart IK, Coles HS, Burne JF, Voyvodic JT, Richardson WD, Raff MC (1992) Cell death and control of cell survival in the oligodendrocyte lineage. Cell 70:31-46.

Barres BA, Schmid R, Sendnter M, Raff MC (1993) Multiple extracellular signals are required for long-term oligodendrocyte survival. Development 118:283-295.

Baud O, Ville Y, Zupan V, Boithias C, Lacaze-Masmonteil T, Gabilan JC, Frydman R, Dehan M (1998) Are neonatal brain lesions due to intrauterine infection related to mode of delivery? Br J Obstet Gynaecol 105:121-124.

Becher B, Fedorowicz V, Antel JP (1996) Regulation of CD14 expression on human adult central nervous system-derived microglia. J Neurosci Res 45:375-381.

Benveniste EN (1994) Cytokine circuits in brain. Implications for AIDS dementia complex. J Nerv Ment Dis 72:71-88.

Benveniste EN, Benos DJ (1995) TNF-alpha and IFN-gamma-mediated 
signal transduction pathways: effects on glial cell gene expression and function. FASEB J 9:1577-1584.

Benveniste EN, Kwon J, Chung WJ, Sampson J, Pandya K, Tang LP (1994) Differential modulation of astrocyte cytokine gene expression by TGF-beta. J Immunol [Erratum (1995) 154:1521] 153:5210-5221.

Benveniste EN, Tang LP, Law RM (1995) Differential regulation of astrocyte TNF-alpha expression by the cytokines TGF-beta, IL-6 and IL-10. Int J Dev Neurosci 13:341-349.

Boje KM, Arora PK (1992) Microglial-produced nitric oxide and reactive nitrogen oxides mediate neuronal cell death. Brain Res 587: $250-256$.

Butt AM, Ibrahim M, Berry M (1997) The relationship between developing oligodendrocyte units and maturing axons during myelinogenesis in the anterior medullary velum of neonatal rats. J Neurocytol 26:327-338.

Cai Z, Pan ZL, Pang Y, Evans OB, Rhodes PG 2000 Cytokine induction in fetal rat brains and brain injury in neonatal rats after maternal lipopolysaccharide administration. Pediatr Res 47:64-72.

Cassaccia-Bonnefil P, Carter B, Dobrowsky R, Chao M (1996) Death of oligodendrocytes mediated by the interaction of nerve growth factor with its receptor p75. Nature 383:716-719.

Chang RC, Hudson PM, Wilson BC, Liu B, Abel H, Hong JS (2000) High concentrations of extracellular potassium enhance bacterial endotoxin lipopolysaccharide-induced neurotoxicity in glia-neuron mixed cultures. Neuroscience 97:757-764.

Chao CC, Hu S, Peterson PK (1995) Modulation of human microglial cell superoxide production by cytokines. J Leukoc Biol 58:65-70.

Constam DB, Phillipp J, Malipiero KV (1992) Differential expression of transforming growth factor-beta 1, -beta 2 and -beta 3 by glioblastoma cells, astrocytes and microglia. J Immunol 148:1401-1410.

Dammann O, Allred EN, Veelken N (1998) Increased risk of spastic diplegia among very low birth weight children after preterm labor or prelabor rupture of membranes. J Pediatr 132:531-535.

Debillon T, Gras-Leguen C, Verielle V, Winer N, Caillon J, Roze JC, Gressens P (2000) Intrauterine infection induces programmed cell death in rabbit periventricular white matter. Pediatr Res 47:736-742.

De Felice C, Toti P, Laurini RN, Stumpo M, Picciolini E, Todros T, Tanganelli P, Buonocore G, Bracci R (2001) Early neonatal brain injury in histologic chorioamnionitis. J Pediatr 138:101-104.

Deguchi K, Mizuguchi M, Takashima S (1996) Immunohistochemical expression of tumor necrosis factor alpha in neonatal leukomalacia. Pediatr Neurol 14:13-16.

D'Souza S, Bonetti B, Balasingam V, Cashman N, Barker P, Troutt A, Raine C, Antel J (1996) Multiple sclerosis: Fas signaling in oligodendrocyte cell death. J Exp Med 184:2361-2370.

Eklind S, Mallard C, Leverin AL, Gilland E, Blomgren K, MattsbyBaltzer I, Hagberg H (2001) Bacterial endotoxin sensitizes the immature brain to hypoxic-ischaemic injury. Eur J Neurosci 13:1101-1106.

Fern R, Moller T (2000) Rapid ischemic cell death in immature oligodendrocytes: a fatal glutamate release feedback loop. J Neurosci 20:34-42.

Gard AL, Pfeiffer SE (1993) Glial cell mitogens bFGF and PDGF differentially regulate development of $\mathrm{O} 4+\mathrm{GalC}$ - oligodendrocyte progenitors. Dev Biol 159:618-630.

Gebicke HP, Appel K, Taylor GD, Schobert A, Rich IN, Northoff H, Berger M (1994) Rat microglial interleukin-3. J Neuroimmunol 50:203-214.

Gibbs RS, Romero R, Hillier SL, Eschenbach DA, Sweet RL (1992) A review of premature birth and subclinical infection. Am J Obstet Gynecol 166:1515-1528.

Gilles FH, Leviton A, Kerr CS (1976) Susceptibility of the neonatal feline telencephalic white matter to a lipopolysaccharide. J Neurol Sci 27:183-191.

Gilles F, Averill D, Kerr C (1977) Neonatal endotoxin encephalopathy. Ann Neurol 2:49-56.

Gilles FH, Leviton A, Dooling EC (1983) The developing human brain: growth and epidemiologic neuropathology. Boston: John Wright, Inc.

Giulian D, Li J, Leara B, Keenen C (1994a) Phagocytic microglia release cytokines and cytotoxins that regulate the survival of astrocytes and neurons in culture. Neurochem Int 25:227-233.

Giulian D, Li J, Li X, George J, Rutecki PA (1994b) The impact of microglia-derived cytokines upon gliosis in the CNS. Dev Neurosci 16:128-136.

Giulian D, Li J, Bartel S, Broker J, Li X, Kirkpatrick JB (1995) Cell surface morphology identifies microglia as a distinct class of mononuclear phagocyte. J Neurosci 15:7712-7726.

Grether JK, Nelson KB, Emery III ES, Cummins SK (1996) Prenatal and perinatal factors and cerebral palsy in very low birth weight infants. J Pediatr 128:407-414.

Grether JK, Nelson KB, Dambrosia JM, Phillips TM (1999) Interferons and cerebral palsy. J Pediatr 134:324-332.

Hansen A, Leviton A (1999) Labor and delivery characteristics and risks of cranial ultrasonographic abnormalities among very-low-birth-weight infants. The Developmental Epidemiology Network Investigators. Am J Obstet Gynecol 181:997-1006.
Hartlage-Rubsamen M, Lemke R, Schliebs R (1999) Interleukin-1beta, inducible nitric oxide synthase, and nuclear factor- kappaB are induced in morphologically distinct microglia after rat hippocampal lipopolysaccharide/interferon-gamma injection. J Neurosci Res 57:388-398.

Hernan MA, Zhang SM, Lipworth L, Olek MJ, Ascherio A 2001 Multiple sclerosis and age at infection with common viruses. Epidemiology 12:301-306.

Hewett J, Hewett S, Winkler S, Pfeiffer S (1999) Inducible nitric oxide synthase expression in cultures enriched for mature oligodendrocytes is due to microglia. J Neurosci Res 56:189-198.

Hickey WF, Kimura H (1988) Perivascular microglial cells of the CNS are bone marrow-derived and present antigen in vivo. Science 239:290-292.

Hickey WF, Vass K, Lassmann H (1992) Bone marrow-derived elements in the central nervous system: an immunohistochemical and ultrastructural survey of rat chimeras. J Neuropathol Exp Neurol $51: 246-256$

Hoshino K, Takeuchi O, Kawai T, Sanjo H, Ogawa T, Takeda Y, Takeda K, Akira S (1999) Cutting edge: toll-like receptor 4 (TLR4)-deficient mice are hyporesponsive to lipopolysaccharide: evidence for TLR4 as the Lps gene product. J Immunol 162:3749-3752.

Imler JL, Hoffmann JA 2000 Toll and toll-like proteins: an ancient family of receptors signaling infection. Rev Immunogenet 2:294-304.

Janeway Jr CA (1992) The immune system evolved to discriminate infectious nonself from noninfectious self. Immunol Today 13:11-16.

Kadhim H, Tabarki B, Verellen G, De Prez C, Rona AM, Sebire G 2001 Inflammatory cytokines in the pathogenesis of periventricular leukomalacia. Neurology 56:1278-1284.

Kaisho T, Akira S (2000) Critical roles of toll-like receptors in host defense. Crit Rev Immunol 20:393-405.

Kurtzke JF, Heltberg A (2001) Multiple sclerosis in the Faroe Islands: an epitome. J Clin Epidemiol 54:1-22.

Lacroix S, Feinstein D, Rivest S (1998) The bacterial endotoxin lipopolysaccharide has the ability to target the brain in upregulating its membrane CD14 receptor within specific cellular populations. Brain Pathol 8:625-640.

Laflamme N, Rivest S (2001) Toll-like receptor 4: the missing link of the cerebral innate immune response triggered by circulating gramnegative bacterial cell wall components. FASEB J 15:155-163.

Lee SC, Liu W, Brosnan CF, Dickson DW (1994) GM-CSF promotes proliferation of human fetal and adult microglia in primary cultures. Glia 12:309-318.

Leviton A, Paneth N, Reuss ML, Susser M, Allred EN, Dammann O, Kuban K, Van Marter LJ, Pagano M, Hegyi T, Hiatt M, Sanocka U, Shahrivar F, Abiri M, Disalvo D, Doubilet P, Kairam R, Kazam E, Kirpekar M, Rosenfeld D, et al. (1999) Maternal infection, fetal inflammatory response, and brain damage in very low birth weight infants. Developmental Epidemiology Network Investigators. Pediatr Res 46:566-575.

Louis JC, Magal E, Takayama S, Varon S (1993) CNTF protection of oligodendrocytes against natural and tumor necrosis factor-induced death. Science 259:689-692.

McDonald JW, Althomsons SP, Hyrc KL, Choi DW, Goldberg MP (1998) Oligodendrocytes from forebrain are highly vulnerable to AMPA/kainate receptor-mediated excitotoxicity. Nat Med 4:291-297.

Means TK, Golenbock DT, Fenton MJ (2000) The biology of toll-like receptors. Cytokine Growth Factor Rev 11:219-232.

Means TK, Jones BW, Schromm AB, Shurtleff BA, Smith JA, Keane J, Golenbock DT, Vogel SN, Fenton MJ (2001) Differential effects of a toll-like receptor antagonist on mycobacterium tuberculosis-induced macrophage responses. J Immunol 166:4074-4082.

Medzhitov R, Janeway Jr CA (1997a) Innate immunity: impact on the adaptive immune response. Curr Opin Immunol 9:4-9.

Medzhitov R, Janeway Jr CA (1997b) Innate immunity: the virtues of a nonclonal system of recognition. Cell 91:295-298.

Medzhitov R, Janeway Jr C (2000) The toll receptor family and microbial recognition. Trends Microbiol 8:452-456.

Merrill JE, Ignarro LJ, Sherman MP, Melinek J, Lane TE (1993) Microglial cell cytotoxicity of oligodendrocytes is mediated through nitric oxide. J Immunol 151:2132-2141.

Mitrovic B, Ignarro LJ, Montestruque S, Smoll A, Merrill JE (1994) Nitric oxide as a potential pathological mechanism in demyelination: its differential effects on primary glial cells in vitro. Neuroscience 61:575-585.

Mizuno T, Sawada M, Marunouchi T, Suzumura A (1994) Production of interleukin-10 by mouse glial cells in culture. Biochem Biophys Res Commun 205:1907-1915.

Molina-Holgado E, Vela JM, Arevalo-Martin A, Guaza C (2001) LPS IFN-gamma cytotoxicity in oligodendroglial cells: role of nitric oxide and protection by the anti-inflammatory cytokine IL-10. Eur J Neurosci 13:493-502.

Moses Jr H, Sriram S (2001) An infectious basis for multiple sclerosis: perspectives on the role of Chlamydia pneumoniae and other agents. BioDrugs 15:199-206.

Nelson KB, Dambrosia JM, Grether JK, Phillips TM (1998) Neonatal 
cytokines and coagulation factors in children with cerebral palsy. Ann Neurol 44:665-675.

Oka A, Belliveau MJ, Rosenberg PA, Volpe JJ (1993) Vulnerability of oligodendroglia to glutamate: pharmacology, mechanisms, and prevention. J Neurosci 13:1441-1453.

O'Shea TM, Klinepeter KL, Meis PJ, Dillard RG (1998) Intrauterine infection and the risk of cerebral palsy in very low-birthweight infants. Paediatr Perinat Epidemiol 12:72-83.

Pang Y, Cai Z, Rhodes PG (2000) Effects of lipopolysaccharide on oligodendrocyte progenitor cells are mediated by astrocytes and microglia. J Neurosci Res 62:510-520.

Park SK, Grzybicki D, Lin HL, Murphy S (1994) Modulation of inducible nitric oxide synthase expression in astroglial cells. Neuropharmacology 33:1419-1423.

Perlman JM, Risser R, Broyles RS (1996) Bilateral cystic periventricular leukomalacia in the premature infant: associated risk factors. Pediatrics 97:822-827.

Poltorak A, He X, Smirnova I, Liu MY, Huffel CV, Du X, Birdwell D, Alejos E, Silva M, Galanos C, Freudenberg M, Ricciardi-Castagnoli P, Layton B, Beutler B (1998) Defective LPS signaling in C3H/HeJ and C57BL/10ScCr mice: mutations in Tlr4 gene. Science 282:2085-2088.

Possel H, Noack H, Putzke J, Wolf G, Sies H (2000) Selective upregulation of inducible nitric oxide synthase (iNOS) by lipopolysaccharide (LPS) and cytokines in microglia: in vitro and in vivo studies. Glia 32:51-59.

Qureshi ST, Lariviere L, Leveque G, Clermont S, Moore KJ, Gros P, Malo D (1999) Endotoxin-tolerant mice have mutations in toll-like receptor 4 (Tlr4). J Exp Med [Erratum (1999) 189:1518] 189:615-625.

Redline RW, Wilson-Costello D, Borawski E, Fanaroff AA, Hack M (2000) The relationship between placental and other perinatal risk factors for neurologic impairment in very low birth weight children. Pediatr Res 47:721-726.

Resch B, Vollaard E, Maurer U, Haas J, Rosegger H, Muller W (2000) Risk factors and determinants of neurodevelopmental outcome in cystic periventricular leucomalacia. Eur J Pediatr 159:663-670.

Schwartz M, Moalem G, Leibowitz-Amit R, Cohen IR (1999) Innate and adaptive immune responses can be beneficial for CNS repair. Trends Neurosci 22:295-299.

Shrikant P, Weber E, Jilling T, Benveniste EN (1995) Intercellular adhesion molecule- 1 gene expression by glial cells. Differential mechanisms of inhibition by IL-10 and IL-6. J Immunol 155:1489-1501.
Takashima S, Mito T, Ando Y (1986) Pathogenesis of periventricular white matter hemorrhages in preterm infants. Brain Dev 8:25-30.

Trapp BD, Nishiyama A, Cheng D, Macklin W (1997) Differentiation and death of premyelinating oligodendrocytes in developing rodent brain. J Cell Biol 137:459-468

Vartanian T, Li Y, Zhao M, Stefansson K (1995) Interferon-gammainduced oligodendrocyte cell death: implications for the pathogenesis of multiple sclerosis. Mol Med 1:732-743.

Volpe JJ (2001) Hypoxic-ischemic encephalopathy. In: Neurology of the newborn. Philadelphia: Saunders.

Woodroofe M (1995) Cytokine production in the central nervous system. Neurology 45:S6-S10.

Woodroofe MN (1991) Detection of IL-1 and IL-6 in adult rat brain, after mechanical injury, by in vivo microdialysis: evidence for a role for microglia in cytokine production. J Neuroimmunol 33:227-236.

Wu YW, Colford Jr JM 2000 Chorioamnionitis as a risk factor for cerebral palsy: a meta-analysis. JAMA 284:1417-1424.

Yonezawa M, Back SA, Gan X, Rosenberg PA, Volpe JJ (1996) Cystine deprivation induces oligodendroglial death: rescue by free radical scavengers and by a diffusible glial factor. J Neurochem 67:566-573.

Yoon BH, Romero R, Yang SH, Jun JK, Kim IO, Choi JH, Syn HC (1996) Interleukin-6 concentrations in umbilical cord plasma are elevated in neonates with white matter lesions associated with periventricular leukomalacia. Am J Obstet Gynecol 174:1433-1440.

Yoon BH, Jun JK, Romero R, Park KH, Gomez R, Choi JH, Kim IO (1997a) Amniotic fluid inflammatory cytokines (interleukin-6, interleukin- $1 \beta$, and tumor necrosis factor- $\alpha$ ), neonatal brain white matter lesions, and cerebral palsy. Am J Obstet Gynecol 177:19-26.

Yoon BH, Kim CJ, Romero R, Jun JK, Park KH, Choi ST, Chi JG (1997b) Experimentally induced intrauterine infection causes fetal brain white matter lesions in rabbits. Am J Obstet Gynecol 177:797-802.

Yucesan C, Sriram S (2001) Chlamydia pneumoniae infection of the central nervous system. Curr Opin Neurol 14:355-359.

Zhang G, Ghosh S 2001 Toll-like receptor-mediated NF-kappaB activation: a phylogenetically conserved paradigm in innate immunity. J Clin Invest 107:13-19.

Zupan V, Gonzalez P, Lacaze-Masmonteil T, Boithias C, d'Allest Mdehan A-M, Gabilan J-C (1996) Periventricular leukomalacia: risk factors revisited. Dev Med Child Neurol 38:1061-1067. 